\title{
Reconfigurações do saber científico e implicações para o ensino superior
}

\author{
Reconfigurations of scientific knowledge and its implications for higher education
}

\author{
Reconfiguraciones del conocimiento científico y sus implicaciones \\ para la educación superior
}

\author{
JosÉ VALDINEI AlbuQUERQUE MiRANDA* \\ GILCILENE DIAS DA COSTA**
}

\begin{abstract}
RESUMO - O texto discute o contexto de crise das metanarrativas legitimadoras da ciência moderna e suas implicações para as instituições de ensino superior no tocante ao ensino, pesquisa e currículos de formação de professores. Seguindo as pistas deixadas por Jean-François Lyotard, em sua obra A condição pós-moderna (2000), o estudo problematiza o processo de introdução de mecanismos técnicos no sistema educacional brasileiro que legitimam um modelo "cientificista" do conhecimento e determina o perfil "neotecnicista" da formação. As análises convergem com a crítica lyotardiana e apontam a insuficiência das metanarrativas modernas diante da coexistência de múltiplos discursos, práticas e racionalidades que permeiam o espaço da vida social e o campo institucional da educação e do currículo. Por fim, ressalta a importância das dimensões integradoras teórica, política e sociocultural nos currículos de formação de professores-pesquisadores no ensino superior.
\end{abstract}

Palavras-chave - Currículo. Formação. Ensino Superior.

ABSTRACT - The text discusses the context of crisis of legislators of modern science metanarrative and its implications for higher education institutions in terms of teaching, research and teacher training curricula. Following the clues left by Jean-François Lyotard, in his work The postmodern condition (2000), the study discusses the process of introduction of technical mechanisms in the Brazilian educational system for making a "scientistic" model of knowledge and determines the profile "neotecnicista" training. The analyses converge with lyotardiana criticism and pointed out the inadequacy of modern metanarratives on the coexistence of multiple discourses, practices and rationalities that permeate the space of social life and the institutional field of education and the curriculum. Finally, it emphasizes the importance of integrative theoretical dimensions, political and sociocultural in curricula of teacherresearchers in higher education.

Keywords - Curriculum. Training. Higher Education.

RESUMEN - El texto analiza el contexto de la crisis de legitimación de los metarrelatos de la ciencia moderna y sus implicaciones para las instituciones de educación superior en relación con la enseñanza, la investigación y el plan de estudios de formación del profesorado. Siguiendo las pistas dejadas por Jean -François Lyotard en su libro La condición postmoderna (2000), el estudio analiza el proceso de introducción de mecanismos técnicos en el sistema educativo brasileño que legitiman un " cientificista " modelo de conocimiento y determina el perfil "formación neotecnicista". Los análisis están de acuerdo con la crítica de Lyotard y señalan la insuficiencia de los metarrelatos modernos en la coexistencia de múltiples discursos, prácticas y racionalidades que permean el espacio de la vida social y el ámbito institucional de la educación y el currículo. Por último, se hace hincapié en la importancia de las dimensiones teóricas, políticas y socioculturales planes de estudio integrador de profesores-investigadores en la educación superior.

Palabras clave - Curriculum. La formación. Educación Superior.

\footnotetext{
* Doutor em Educação pela Universidade Federal do Rio Grande do Sul (Porto Alegre, RS, Brasil) e Professor na Universidade Federal do Pará (Belém, PA, Brasil).E-mail:<jneimiranda@ufpa.br>.

**Doutora em Educação pela Universidade Federal do Rio Grande do Sul (Porto Alegre, RS, Brasil) e Professora na Universidade Federal do Pará (Belém, PA, Brasil).E-mail:<ghiscosta@ufpa.br>.
} 


\section{INTRODUÇÃO}

A partir das análises de Jean-François Lyotard em sua obra A condição pós-moderna (1979/2000), o presente texto discute o contexto de crise das metanarrativas educacionais e suas implicações para o campo do currículo e da formação de professorespesquisadores no ensino superior, mediante a crítica da introdução de mecanismos técnicos (como os critérios de "performance" e "produtividade") que legitimam um modelo "cientificista" de produção do conhecimento e determina o perfil "neotecnicista" da formação. Nesse cenário entra em curso um intenso processo de mudança paradigmática do conhecimento, o qual incide na própria natureza da Ciência e da Universidade, motivado pelo impacto das transformações tecnológicas sobre o saber científico.

A partir da década de 1950 (com o início da "era pósindustrial"), os estatutos epistemológicos das ciências modernas e das universidades passam por substantivas transformações. De acordo com Lyotard (2000), uma das consequências imediatas provocadas por esse novo cenário recobre o quadro teórico erigido pela filosofia moderna (metafísica ${ }^{1}$ ), cuja fundamentação se estruturava em metarrelatos explicativos sobre a natureza epistemológica das ciências. Com isso, os pressupostos teóricos e filosóficos do paradigma da ciência moderna são questionados motivando, de um lado, uma crise de legitimação dos meta-sistemas explicativos, de outro, a emergência de critérios técnicos e instrumentais de justificação do saber científico pautado nas noções de "produtividade" e "desempenho", ou seja, entra em cena um modelo cientificista de conhecimento cujos pressupostos já não se pautam na busca pela "verdade", e sim, na funcionalidade operacional da ciência visando o aumento do desempenho tecnológico.

Com o advento dessa "concepção operacional da ciência"(LYOTARD, 2000), as funções de "descobrir" ou "afirmar" a verdade cedem lugar à localização do "erro" como algo negativo a ser superado rumo ao aumento da eficácia produtiva do conhecimento (uma lógica inversa à noção de erro científico em Karl Popper, para quem o erro é algo positivo capaz de abrir novas possibilidades de respostas e caminhos na busca da verdade). A pesquisa científica, nesse novo regime de produção, passa a ser condicionada pelas possibilidades técnicas da máquina informática, e o que escapa ou transcende tais possibilidades tende a não ser operacional, já que não pode ser traduzido em linguagem informatizada, ou seja, em "bits" de informações. Com isso, as experiências e vivências de formação como algo capaz de nos educar e nos transformar com significativos aprendizados são cada vez mais reduzidas ao nível das opiniões e das informações traduzidas em linguagem decodificada e informatizada ("bits" de informação).

Analisando o contexto de crise de legitimação do saber científico, Lyotard (2000) considera que uma das características marcantes da filosofia moderna (metafísica) consistiu em transformar a filosofia em um metadiscurso de legitimação da própria ciência. A dialética do espírito e a emancipação do sujeito são exemplos da busca por uma fundamentação que assegurasse a legitimidade da ciência a partir de um metarrelato filosófico. A ciência, para a filosofia moderna, herdeira do iluminismo, assumia seu estatuto de legitimidade como auto-referência, ou seja, existia e se renovava com base em si mesma; era vista como uma atividade nobre, sem finalidade pré-estabelecida, sendo que "sua função primordial era romper com mundo das 'trevas', mundo do senso comum e das crenças tradicionais contribuindo, desse modo, para o desenvolvimento moral e espiritual da nação" (BARBOSA, 2000, p. IX). Nesse contexto, a ciência não era vista como valor de uso, mas fundava sua legitimidade a partir do ideal de formação de um sujeito livre, racional e emancipado.

Originalmente a ciência entra em conflito com os relatos (fábulas). Exerce sobre seu próprio estatuto um discurso de legitimação, chamado de filosofia. Quando este metadiscurso recorre explicitamente a um grande relato, como a dialética do espírito, a emancipação do sujeito racional ou do trabalhador, chama-se moderna a ciência que a isso se refere para se legitimar (LYOTARD, 2000, p. XV).

Lyotard (2000) identifica dois grandes relatos filosóficos que serviram de fundamentação para legitimar o saber científico na modernidade: De um lado, $a$ fundamentação especulativa - que investia na formação do espírito do sujeito, da pessoa e da humanidade. Esse metarrelato marca o pensamento alemão através da "filosofia do espírito absoluto" que justifica o estatuto da própria Universidade com a difusão da pesquisa e do conhecimento não por um princípio de eficiência e uso, mas por um princípio de formação do espírito do sujeito para a elevação cultural da humanidade. De outro lado, os fundamentos iluministas - baseados no princípio da "emancipação do sujeito racional ou do trabalhador". Esse grande relato marca o pensamento francês que recebeu forte influência da filosofia política de Marx e da realização do estado positivo de Augusto Conte. Percorrendo diferentes perspectivas tais fundamentos iluministas centram-se nos princípios da Ciência, da Nação e do Estado, e na emancipação do sujeito como elemento que alavanca o progresso.

No momento em que esses metarrelatos já não conseguem responder às demandas das múltiplas racionalidades emergentes no cenário pós-moderno os 
fundamentos da ciência moderna entram em crise $^{2}$ e com ela os modelos de produção e justificação do saber científico e das próprias instituições universitárias, em decorrência da impossibilidade de legitimação ${ }^{3}$ ou enquadramento de um metadiscurso metafísico de justificação da ciência moderna em tempos atuais. Lyotard considera que o pós-moderno, ${ }^{4}$ enquanto condição da cultura nesta era caracteriza-se exatamente pela incredulidade perante o fundamento filosófico-metafísico (tanto de caráter especulativo quanto emancipador), com suas pretensões universalistas de verdade. Nas palavras do autor:

Simplificando ao extremo, considera-se 'pós-moderna' a incredulidade em relação aos metarrelatos. É sem dúvida, um efeito do progresso das ciências; mas este progresso, por sua vez, a supõe. Ao desuso do dispositivo metanarrativo de legitimação corresponde a crise da filosofia metafísica e a da instituição universitária que dela dependia. A função narrativa perde seus atores (functeurs) os grandes heróis, os grandes perigos, os grandes périplos e o grande objetivo. Ela se dispersa em nuvens de elementos de linguagem narrativos, mas também denotativos, prescritivos, descritivos etc., cada uma veiculando consigo validades pragmáticas sui generis. Cada um de nós vive em muitas destas encruzilhadas. Não formamos combinações de linguagem necessariamente estáveis, e as propriedades destas por nós formadas não são necessariamente comunicáveis (LYOTARD, 2000, p. XVI).

Desse modo, a atividade científica deixa de ser aquela práxis que, segundo a avaliação humanísticoliberal especulativa, investia na formação do "espírito", do "sujeito", da "humanidade". Com ela, o que vem se impondo é uma concepção de ciência como tecnologia intelectual capaz de produzir conhecimentos em "bits de informações" e com amplo valor de circulação e de troca, ou seja, uma prática produtiva submetida ao capital e ao Estado operando como particular mercadoria chamada força de produção.

Esse processo, fruto da corrosão dos dispositivos modernos de explicação da ciência, é denominado por Lyotard (2000) pela expressão "deslegitimação".5 O processo de deslegitimação caracteriza-se pela impossibilidade de submeter todos os discursos ou "jogos de linguagem"6 à autoridade de um metadiscurso que se pretende síntese integradora de todos os discursos, isto é, um discurso que possa servir de modelo de linguagem (sistema) e que apresente uma verdade universal.

Diante do contexto de crise dos metarrelatos da ciência moderna surgem inúmeras indagações relativas ao campo do conhecimento científico, dos currículos de formação e das instituições de ensino superior no tocante: à construção de parâmetros epistemológicos, éticos e políticos que edifiquem a legitimidade do saber científico e das instituições formadoras; à criação de currículos e conhecimentos que levem em conta os múltiplos jogos de linguagem existentes no campo da formação; enfim, aos discursos disputam a legitimidade do currículo, da pesquisa e da formação de professores no cenário atual das instituições de ensino superior.

Sabemos que as disputas por legitimação do saber científico no campo do currículo e da formação de professores e pesquisadores são inseparáveis das relações de poder e das lutas por afirmações de significados e verdades. Nessa disputa por significações coexiste uma permanente tensão entre tentativas de delimitação, fixação e regulamentação de determinados discursos e conhecimentos e a rebeldia, o deslizamento e a disseminação de sentidos que inviabilizam a captura dos significados. É justamente esse jogo de forças em torno de significados e discursos que transitam no campo do currículo que atribuem ao saber científico um caráter incerto, indeterminado e imprevisível, tornando-o um permanente território de disputas de poder por novas formas de legitimação do saber científico.

\section{CURRÍCULO E ENSINO SUPERIOR: PRODUTIVIDADE DO CONHECIMENTO E ESQUIZOFRENIA CIENTÍFICA}

O processo de "deslegitimação" ocorrido com a crise dos metarrelatos do saber científico provoca profundas mudanças no estatuto das ciências e nas instituições de ensino superior. A compreensão de que o saber científico não pode mais ser justificado e legitimado a partir de fundamentos metafísicos, instaura não apenas a crise de conceitos caros ao pensamento moderno, tais como "razão", "sujeito", "totalidade", "verdade", "progresso", como também reconfigura o campo das ciências. Conhecimentos científicos entram em crise, verdades aceitas universalmente são abaladas, quebramse fronteiras disciplinares, enfim, ocorre uma significativa reconfiguração no estatuto epistemológico da ciência e na organização institucional do saber científico.

Ao lado dessa crise de legitimidade, Lyotard (2000) aponta o surgimento de novos enquadramentos teóricos e tecnológicos, tais como: o aumento da potência na produtividade, a eficiência e eficácia na realização das atividades, a otimização das performances do sistema, o desenvolvimento de competências operacionais e habilidades na formação profissional visando ao aumento do desempenho. Esses novos critérios operam como legitimadores do saber científico, da produção tecnológica e, consequentemente, estendem-se para o campo da pesquisa, do currículo e da formação de diferentes profissionais em nível superior. 
Em decorrência dessa crise de pressupostos, o gerenciamento e a legitimação do saber científico passam a ser controlados por um novo "jogo de linguagem" pautado nos critérios de produtividade e desempenho. Para exemplificar esse novo quadro de mudanças paradigmáticas no campo do saber científico atual, no tocante à pesquisa acadêmica configurada como um novo modelo de tecnologia intelectual observa-se, nos últimos anos, no âmbito das pesquisas em educação no Brasil (e isso certamente se aplica a outras áreas do conhecimento) uma nítida exigência por parte das instâncias governamentais de fomento à pesquisa científica e das instituições de ensino superior, em geral, em elevar cada vez mais os índices quantitativos de produtividade do conhecimento considerados parâmetros de inovação e excelência científica. Indispensáveis dessa "missão" em contribuir com o avanço acelerado do conhecimento e das tecnologias científicas, os pesquisadores, nas mais distintas áreas, são levados a desenvolver suas atividades acadêmicas sob uma forte pressão institucional, movidos pela rapidez em produzir e publicar incontáveis "inovações científicas". Esse novo cenário configurado pelo aumento da produtividade no campo da produção do conhecimento acaba gerando o que podemos chamar de um estado de esquizofrenia científica, no qual os professores-pesquisadores amplamente se mobilizam frente à exigência de produzir/publicar conhecimentos "inovadores", que passam a circular em mundos distintos, muitas vezes paralelos e desconexos, desencontrados ou invisíveis nesse vasto universo de produtividade do saber científico.

A Universidade, situada nesse contexto, torna-se uma instituição bastante visada na consolidação de uma tecnologia intelectual e no cálculo estratégico-político dos Estados. Sua capacidade em produzir conhecimentos científicos e novas tecnologias de mercado é condição de exigência para a entrada de investimentos capitais ao campo da pesquisa com vistas ao aumento da "performance científica" em seus resultados. Nesse cenário, as instituições universitárias tem se tornado um ambiente marcado predominantemente por pressões de competitividade e desempenho quantitativo do conhecimento. Um novo vocabulário de mercado passa a governar os objetivos e os rumos de seu funcionamento: competitividade, performance, desempenho, eficiência, produtividade, metas, resultados, autogerenciamento, etc. Seus mecanismos de legitimação assumem uma estreita vinculação com os princípios operacionais da ciência aliados ao do mercado, ou seja, as instituições universitárias passam a ser legitimadas por um dispositivo técnico fazendo com que o discurso da melhor performance ou desempenho assuma o centro de suas determinações. Essa nova forma de legitimação reconfigura o campo do saber científico e do currículo, estabelece hierarquias entre as instituições de ensino superior, enfim, transforma a relação das instituições universitárias com os conhecimentos por elas produzidos:

Se a revolução industrial nos mostrou que sem riqueza não se tem tecnologia ou mesmo ciência, a condição pós-moderna nos vem mostrando que sem saber científico e técnico não se tem riqueza. Mais do que isto: mostra-nos, através da concentração massiva, nos países ditos pós-industriais, de bancos de dados sobre todos os saberes hoje disponíveis, que a competição econômico-política entre as nações se dará daqui para frente não mais em função primordial da tonelagem anual de matéria-prima ou de manufaturados que possam eventualmente produzir. Dar-se-á, sim, em função da quantidade de informação técnico-científica que suas universidades e centros de pesquisa forem capazes de produzir, estocar e fazer circular como mercadoria. (BARBOSA, 2000, p. XI)

Isso mostra que o contexto de deslegitimação do saber científico se configura, paradoxalmente, como um dispositivo de legitimação de novos discursos e critérios de funcionamento, uma vez que o espaço deixado pelos metadiscursos legitimadores da ciência moderna é novamente disputado por um jogo de forças e relações de poder de grupos que lutam permanentemente para instituir seus discursos e garantir sua hegemonia.

No campo do currículo, entendido como espaço de disputas e lutas por significações de valores e conhecimentos, podemos observar a coexistência de forças que flutuam entre as tentativas de delimitação, fixação e naturalização do significado (currículo tradicional), e a rebeldia que dissemina múltiplas formas de conceber e pensar as fronteiras do currículo e da educação (currículo crítico e pós-crítico). Moreira (1997) reitera essa coexistência de forças e disputas que perpassam o campo do currículo ao considerar que:

\begin{abstract}
O currículo constitui significativo instrumento utilizado por diferentes sociedades tanto para desenvolver os processos de conservação, transformação e renovação dos conhecimentos historicamente acumulados como para socializar as crianças e os jovens segundo valores tidos como desejáveis. Em virtude da importância desses processos, a discussão em torno do currículo assume cada vez mais lugar de destaque no conhecimento pedagógico. (MOREIRA, 1997, p. 11)
\end{abstract}

Considerando-se que a busca por legitimidade de saberes no campo das ciências e dos currículos de formação superior perpassa um jogo de forças sempre em aberto, é importante que suscitemos o debate sobre essas novas configurações paradigmáticas da pesquisa científica e formação acadêmica em curso. Nesse novo 
cenário onde coexistem múltiplas racionalidades em disputa por legitimidade do saber científico, as instituições de ensino superior e seus currículos de formação são levados a assumir novos modelos de justificação. Nas palavras de Lyotard (2000, p. 92-93), "a perspectiva de um vasto mercado de competência operacional está aberto": formam-se pesquisadores ou profissionais, investe-se na pesquisa e na sua infra-estrutura não mais com o objetivo de formar indivíduos emancipados, com espíritos livres, culturalmente educados e tendo como princípio a busca da verdade, mas sim, com o propósito de formar competências operacionais e desenvolver habilidades capazes de saturar as funções necessárias ao bom desempenho da dinâmica institucional.

\section{PENSAR A UNIVERSIDADE, REPENSAR A FORMAÇÃO}

No ensino superior brasileiro dos tempos atuais, observa-se uma intensa busca por produtividade do conhecimento em diferentes áreas. Com isso, o saber científico é colocado em efusiva circulação, exigindo dos pesquisadores novas configurações no processo de formação acadêmica e profissional, caminhando lado a lado com as demandas de mercado. Nesse novo cenário,

$\mathrm{O}$ antigo princípio segundo o qual a aquisição do saber é indissociável da formação (Bildung) do espírito, e mesmo da pessoa, cai e cairá cada vez mais em desuso. Esta relação entre fornecedores e usuários do conhecimento e o próprio conhecimento tende e tenderá a assumir a forma que os produtores e os consumidores de mercadorias têm com essas últimas, ou seja, a forma valor. O saber é e será produzido para ser vendido, e ele é e será consumido para ser valorizado numa nova produção: nos dois casos, para ser trocado. Ele deixa de ser para si mesmo seu próprio fim; perde o seu 'valor de uso' (LYOTARD, 2000, p. 04-05).

Isso faz com que os conhecimentos em vez de serem difundidos por seu "valor formativo" ou por de sua "importância política" na emancipação dos sujeitos sociais, sejam postos em circulação seguindo os critérios de eficiência, desempenho e "valor de troca" que caracterizam as relações de mercado. Essa relação de troca estabelecida com o conhecimento tende a ser assumida pelas políticas de formação de professores e a determinar o currículo, a pesquisa e os rumos (objetivos e finalidades) das instituições de ensino superior.

Nesse quadro axiológico de mudanças, áreas de conhecimentos são colocadas em questão e passam a ser desvalorizadas, discussões sobre problemas políticos, econômicos, culturais e sociais abrem espaço para a utilização mercadológica do saber científico, enfim, os princípios operacionais da ciência passam a legitimar o saber científico e a determinar as regras do jogo das instituições universitárias. Estabelece-se uma equação entre riqueza, eficiência e verdade, e um dispositivo técnico tende a determinar os critérios da legitimação do saber científico exigindo, com isso, um grande investimento em certas áreas do conhecimento para otimizar a performance ao qual é aplicado. O Estado e as instituições financiadoras abandonam o relato de legitimação idealista ou humanista e passam a assumir como critério de investimento em pesquisas e formação profissional, a produção de novas tecnologias e a formação de profissionais capazes de manter o sistema em pleno funcionamento, desenvolvendo competências operacionais necessárias que possibilitem melhorar o desempenho de suas performances. "O critério de bom desempenho é explicitamente invocado pelas administrações para justificar a recusa de apoiar este ou aquele centro de pesquisas" (LYOTARD, 2000, p. 85).

Como consequência desse processo, o ensino e o currículo se veem afetados diretamente pela prevalência do critério de desempenho na legitimação do saber e das instituições superiores. Perguntas como: quais conhecimentos deverão ser selecionados e incluídos nos currículos de formação?, em que consiste sua funcionalidade?, que métodos e estratégias de ensino utilizar?, para qual finalidade?, se tornam questões determinantes para o desenvolvimento de uma política de formação universitária. A busca por adequação de respostas a esses desafios passam a orientar os modelos de elaboração curricular e de ensino, visando o melhor desempenho dos professores em sua área de formação e atuação. Com isso, o resultado da formação a ser alcançado tende cada vez mais a uma máxima contribuição do ensino superior ao bom funcionamento do mercado.

\begin{abstract}
No contexto da deslegitimação, as universidades e as instituições de ensino superior são de agora em diante solicitadas a formar competências, e não mais ideais: tantos médicos, tantos professores de tal ou qual disciplina, tanto engenheiros, administradores, etc. A transmissão dos saberes não aparece mais como destinada a formar uma elite capaz de guiar a nação em sua emancipação. Ela fornece ao sistema os jogadores capazes de assegurar convenientemente seu papel junto aos postos pragmáticos de que necessitam as instituições (LYOTARD, 2000, p. 89).
\end{abstract}

No tocante aos propósitos formativos das instituições de ensino superior, sua ênfase parece não mais recair na busca pela construção de conhecimentos agregados à sua importância política, histórica ou filosófica, mas sim, nas competências operacionais a serem desenvolvidas e aplicadas nas devidas áreas do saber. Dominar a linguagem da informática, ocupar o ranking da produtividade 
científica, exercer liderança e empregar adequadamente habilidades e competências comunicativas, saber administrar sua carreira profissional, ter um currículo produtivo e diversificado, são competências que devem ser desenvolvidas nos estudantes durante o processo de formação, como forma de garantir a melhor performance profissional e a otimização de desempenho no mercado de trabalho:

A questão explícita ou não, apresentada pelo estudante profissionalizante, pelo Estado ou pela instituição de ensino superior não é mais: isto é verdadeiro? mas: para que serve isto? No contexto da mercantilização do saber, esta última questão significa comumente: isto é vendável? E, no contexto do aumento do poder: isto é eficaz? (...) A perspectiva de um vasto mercado de competências operacionais está aberta. (LYOTARD, 2000, p. 92-93)

Quanto às mudanças paradigmáticas em âmbito institucional, a tendência é que o princípio de articulação entre ensino, pesquisa e extensão - que caracteriza historicamente as instituições superiores - seja rompido, criando-se uma hierarquia no nível superior entre Universidades, Centros de Excelência e Institutos ou Escolas Superiores, e ainda, uma separação entre produção do saber (pesquisa) e sua transmissão (ensino). A tendência para a qual se orientam muitas instituições de ensino, especificamente no Brasil, consiste em dissociar esses dois aspectos - o da produção e o da reprodução - distinguindo as instituições voltadas à produção do saber científico e de novas tecnologias, e as instituições destinadas à reprodução de conhecimentos operacionais com ênfase na expansão do ensino superior.

Tais mudanças encontram-se amparadas em mecanismos legais e instâncias governamentais que determinam a atual política educacional brasileira criando, no nível superior, uma hierarquização entre Universidades capazes de promover a produção de novos conhecimentos e tecnologias inovadoras no campo do saber científico, e Escolas ou Institutos de Educação Superior, estas últimas assumindo a função de reproduzir, ou melhor, distribuir e socializar os conhecimentos através de cursos de curta duração destinados a formar profissionais em diferentes áreas visando atender as demandas de mercado. Por conta disso decorre uma verdadeira diferenciação e estratificação das instituições de ensino superior segundo o tipo de conhecimento produzido, o grau de produtividade científica e as diferentes finalidades que cada instituição formadora define frente aos seus propósitos.

Orientados pela lógica do melhor desempenho, os currículos das instituições de ensino superior passam a assumir finalidades basicamente funcionais, e os cursos de formação tendem a dedicar grande ênfase às dimensões técnica e prática da formação e à concepção operacional do conhecimento. Princípios de uma racionalidade instrumental ${ }^{7}$ passam a governar a política oficial de formação e procuram realizar um maior aprimoramento no "saber fazer", a fim de possibilitar aos professores durante o processo de sua formação uma maior eficiência nas atividades específicas de sua área de atuação reeditando, em tempos atuais, uma lógica "neotecnicista" da educação. Essa lógica "neotecnicista" é responsável, em grande parte, pela legitimação de um discurso educacional, amplamente difundido no ensino superior, voltado para o desenvolvimento de competências e habilidades colocadas no centro dos currículos de formação de professores.

Não obstante, os conhecimentos a serem trabalhados no decorrer dos cursos tendem a ser incluídos não com base no critério de sua relevância histórica, política e sociocultural, mas sim, no critério de sua operacionalização. Questões como: que articulações teóricas e práticas os professores-pesquisadores devem estabelecer com os conhecimentos estudados?, que elementos históricos, culturais, políticos e filosóficos devem se fazer presentes na formação desses profissionais?, quais conhecimentos curriculares possibilitam aos professores-pesquisadores uma ampla compreensão dos problemas educacionais e das contradições socioeconômicas presentes em sua realidade? Questões como essas acabam sendo silenciadas ou mesmo suprimidas por perguntas do tipo: qual a funcionalidade prática dos conhecimentos?, como e onde aplicar determinados conteúdos e teorias?, de que maneira os conhecimentos acadêmicos poderão auxiliar na resolução de problemas práticos e imediatos do fazer pedagógico?

A partir dessa inversão epistemológica e axiológica em torno da construção e da finalidade do conhecimento, dimensões de ordem histórica, política, cultural e filosófica são cada vez mais secundarizadas no processo de formação de professores em nome de uma busca exacerbada pela praticidade operacional de conhecimentos acadêmicos e escolares. Fortemente amparada na retórica do professor tecnicamente competente, a atual política de currículo oficial, no Brasil, desloca as discussões de base teórica, social e política da formação dos professores para a dimensão do aprimoramento do saber fazer, no qual o professor é convocado a mobilizar saberes práticos em situações concretas, a fim de obter maior eficiência nas suas atividades em sala de aula. De acordo com Macedo e Moreira (2001, p. 121), "uma formação docente centrada no conhecimento, na cultura e na crítica cede lugar a uma formação centrada em competências, reconfigurando-se a imagem e a tarefa do professor e associando-se, de modo estreito, a escola, a formação do professor e o mundo produtivo". 
A concepção tecnicista de educação e de currículo, que alcançou grande vigor no pensamento educacional brasileiro na década de 1970, debatida e criticada na década de 1980, parece retornar com grande vigor no contexto atual e assumindo novas configurações. Ao que parece, essa política "neotecnicista" de formação de professores visa estabelecer um amplo controle e diretividade do conhecimento através da definição de objetivos e metas a serem alcançados pelas instituições formadoras em consonância com as demandas de mercado.

Em face das incertezas do mercado de trabalho e da volatilidade das formações profissionais que ele reclama, considera-se que é cada vez mais importante fornecer aos estudantes uma formação cultural sólida e ampla, quadros teóricos e analíticos gerais, uma visão global do mundo e das suas transformações de modo a desenvolver neles o espírito crítico, a criatividade, a disponibilidade para a inovação, a ambição pessoal, a atitude positiva perante o trabalho árduo e em equipe, e a capacidade de negociação que os preparem para enfrentar com êxito as exigências cada vez mais sofisticadas do processo produtivo. (SANTOS, 1989, p. 23)

Transmutada de uma formação humanista e geral, a tendência neotecnicista parece pretender recuperar o valor de uma formação cultural sólida, primando por aspectos qualitativos dessa formação. No entanto, conforme podemos observar na descrição acima assinalada por Santos (1989), tal perfil de formação aponta, em verdade, para um "regresso ao generalismo" com vistas a um "desempenho plurifuncionalizado", flexível e volátil às demandas e exigências de mercado.

No bojo dessa reconfiguração, o foco principal da política de formação "neotecnicista" vem caminhando a passos largos no sentido de legitimar o saber científico, as instituições de ensino superior e, consequentemente, o currículo de formação de professores através do discurso da otimização da performance e do melhor desempenho funcional. As instituições de ensino superior, por sua vez, atravessam momentos de tensão entre, de um lado, terem de assumir fins estritamente funcionais e as metas de mercado, de outro, a atribuição política de formar sujeitos críticos e emancipados, culturalmente educados para o exercício da cidadania. Corroborando com Santos (1989), acreditamos que a universidade, nessa fase de transição paradigmática, precisa criar alternativas ao seu próprio regime de funcionamento quando este se vê diretamente atrelado à logica de mercado, uma vez que "a universidade, ao aumentar a sua capacidade de resposta, não pode perder a sua capacidade de questionamento", a sua autonomia institucional e organizacional, bem como o seu compromisso com uma formação sólida e plural.

\section{CONSIDERAÇÕES FINAIS}

O diagnóstico traçado por Lyotard (2000) no tocante às mudanças históricas transcorridas no campo do saber científico emanadas no cerne da crise da ciência moderna (mudanças predominantemente marcadas pela "concepção operacional da ciência" e direcionadas para a melhor performance de produtividade científica e desempenho profissional), nos conduz a uma análise crítica sobre as perspectivas que orientam a produção científica do conhecimento e o papel das universidades como lugar de formação cultural e construção de saberes socialmente comprometidos a despeito das demandas de mercado. Tal diagnóstico nos lança provocações na direção de pensar e problematizar o campo da produção do conhecimento, da pesquisa e da formação superior enredado por relações de poder e interesses políticos e econômicos. Parafraseando Silviano Santiago, podemos dizer que o diagnóstico da condição pós-moderna traçado por Lyotard não opera como uma sentença, mas "existe para que avaliemos até que ponto é justo e verdadeiro o seguinte: 'Não se compram cientistas, técnicos e aparelhos para saber a verdade, mas para aumentar o poder"” (SANTIAGO, 2000, p. 131).

Isso nos leva a questionar o fato de que os currículos de formação, ao se constituírem em artefatos envolvidos na dinâmica de fabricação de saberes e discursos que atualmente instituem a lógica da competência, do desempenho, do sucesso e do fracasso institucional no ensino superior, também devem ser vistos como um campo passível de discussão, problematização e novas proposições, uma vez que eles transcendem o campo representacional da política institucional e efetivam a produção dos discursos dos quais fala. Mais que isso, o currículo, esse componente produtor e articulador de práticas e concepções pedagógicas, opera de modo a produzir os próprios sujeitos que interpela. Fabricado em meio a uma rede de disputas e poderes, "o currículo estabelece diferenças, constrói hierarquias, produz identidades" (SILVA, 2001, p. 12) que precisam ser discutidas e permanentemente tensionadas, na medida em que funciona como um poderoso dispositivo que subjetiva, interpela e recoloca os indivíduos e as instituições numa posição hierárquica de lugares e privilégios a depender dos resultados produtivos alcançados por seus desempenhos.

Esse quadro de mudanças remete à busca por novas configurações teórico-práticas no campo do currículo e da formação de professores e instaura, no âmbito das instituições de ensino superior, uma disputa permanente de forças entre grupos em torno da "garantia" de sua legitimidade e hegemonia: de um lado, a busca por uma formação "neotecnicista" com base em critérios da melhor performance e otimização do desempenho técnico-profissional; de outro, a busca por uma formação 
acadêmica articuladora das dimensões filosófica, política, sociocultural.

As determinações atuais da política de currículo e de formação de professores no Brasil seguem, em linhas gerais, as orientações que apontam para a construção de competências e habilidades operacionais visando o melhor desempenho técnico-profissional. Entretanto, como são múltiplos os discursos e as racionalidades que atuam no campo da educação e do currículo, sendo nosso papel enquanto professores e pesquisadores produzir outros discursos que levem em consideração a multidimensionalidade do processo educativo e a pluralidade de ideias, valores e práticas pedagógicas e socioculturais que coexistem no atual contexto da educação brasileira.

Concluímos, por fim, que as universidades enquanto instituições de ensino que historicamente instituíram espaços de crítica e autocrítica de seu papel e atuação na sociedade, primando pela formação de profissionais qualificados, pela produção científica inovadora de conhecimentos e práticas alternativas em seu interior, colocando-se o desafio de questionar os rumos da ciência e da formação e responder criticamente às necessidades e aos desafios atualmente colocados pelo modelo paradigmático da nova ciência codificada em parâmetros cientificistas da formação. As universidades devem possibilitar a pesquisadores e estudantes uma sólida formação filosófica, política e sociocultural, de modo a contribuir para a construção de um pensar crítico e uma agir comprometido com a busca de compreensão de problemas históricos e emergentes no campo da educação, podendo aumentar a sua capacidade de resistência e alternativas ao paradigma cientificista e à tendência neotecnicista que pairam sobre o campo do conhecimento e da formação superior.

\section{REFERÊNCIAS}

BARBOSA, Wilmar do Valle. Tempos pós-modernos. In: LYOTARD, Jean-François. A condição pós-moderna. 6. ed. Rio de Janeiro: José Olympio, 2000.

BRASIL. MINISTÉRIO DA EDUCAÇÃO E DO DESPORTO (MEC). Proposta de diretrizes para a formação inicial de professores da educação básica, em curso de nível superior. Maio/2000.

HABERMAS, Jürgen. Pensamento pós-metafísico. São Paulo: Tempo Brasileiro; BTU, 1990.

LARROSA, Jorge. Nietzsche \& a educação. Belo Horizonte: Autêntica, 2002.

LYOTARD, Jean-François. A condição pós-moderna. 6. ed. Rio de Janeiro: José Olympio, 2000.

MACEDO, Elizabeth. Formação de professores e diretrizes curriculares nacionais: para onde caminha a educação? Teias, Rio de Janeiro, n. 2, p. 7-18, jul.-dez. 2000.
MACEDO, Elizabeth; MOREIRA, Antonio Flávio. Em defesa de uma orientação cultural na formação de professores. In: CANEN, Ana; MOREIRA, Antonio Flávio (Org.). Ênfases e omissões no currículo. Campinas, São Paulo: Papirus, 2001.

MOREIRA, Antonio Flavio Barbosa (Org.). Currículo: questões atuais. Campinas, São Paulo: Papirus, 1997.

SANTOS, Boaventura de Sousa. Da ideia de universidade à universidade de ideias. Revista Crítica de Ciências Sociais, Coimbra, n. 27/28, p. 11-62, jun. 1989.

SANTOS, Boaventura de Sousa. Pela mão de Alice: o social e o político na pós-modernidade. Porto, Portugal: Afrontamento, 2000.

SILVA, Tomaz Tadeu da. Documentos de identidade: uma introdução às teorias do currículo. Belo Horizonte: Autêntica, 2000.

SILVA, Tomaz Tadeu da. O currículo como fetiche: a poética e a política do texto curricular. Belo Horizonte: Autêntica, 2001.

WITTGENSTEIN, Ludwig. Investigações filosóficas. 2. ed. Petrópolis, RJ: Vozes, 1994.

\section{Notas}

1 Habermas em sua obra Pensamento pós-metafísico (1990) apresenta quatro aspectos que se fazem presentes na filosofia metafísica da modernidade: o pensamento da identidade, o pensamento unitário da filosofia idealista, a compreensão da filosofia como filosofia da consciência e o conceito forte da teoria, ou seja, a força totalizadora da teoria. Nesse aspecto, poderíamos aproximar o pensamento de Habermas ao de Lyotard, pois ambos encontram-se situados em um horizonte teórico que não procura sua fundamentação ou legitimação em um fundamento metafísico. Entretanto, o caminho posterior à queda da fundamentação última em Habermas segue a construção da teoria da ação comunicativa, enquanto Lyotard situa-se na teoria dos jogos de linguagem aproximando-se do pensamento de Wittgenstein.

2 Como complemento às discussões levantadas por Lyotard acerca do conceito de "crise" que configura o atual cenário da ciência moderna, utilizaremos a expressão "narrativa de crise" discutida por Jorge Larrosa no livro Nietzsche \& a Educação (2002), para caracterizar o dinamismo histórico dos contextos de crise como "um tipo de narrativa que constrói o presente como um momento crítico no duplo sentido da palavra, como um momento decisivo e ao mesmo tempo como um momento de crítica, como um momento no qual o sujeito recupera criticamente sua própria história, apropria-se criticamente de sua própria história, para saber onde se encontra e para decidir seu próprio movimento. Talvez por isso, os relatos de crise tenham esse tom apocalíptico, esse tom de fim de mundo, esse tom de grandes apostas e grandes decisões, esse tom de morte e renascimento, esse tom de estado crítico, de enfermidade quase mortal e remédios desesperados, esse tom heroico, esse tom, definitivamente, de perdição ou salvação" (LARROSA, 2002, p. 89-90).

3 Legitimação (legitimar + ação) ato ou efeito de tornar legítimo para todos os efeitos da lei. Boaventura Santos (2000), em sua análise sobre a crise da universidade, apresenta três crises que afetam diretamente as Universidades: a crise de hegemonia. Há uma crise de hegemonia sempre que uma dada condição social deixa de ser considerada necessária, única e exclusiva; a crise de legitimidade. Há uma crise de legitimidade sempre que uma dada condição social deixa de ser consensualmente aceita; $a$ crise institucional. Há uma crise institucional sempre que uma dada condição social estável e autossustentada deixa de poder garantir os pressupostos que asseguram a sua reprodução. Santos descreve a crise de legitimidade com ênfase nas mudanças epistemológicas e nas transformações das condições sociais. Lyotard (2000) analisa o processo de legitimação da ciência moderna vinculado aos metarrelatos, considerando que as modificações substantivas no estatuto das ciências e das instituições universitárias provocadas pelo impacto das transformações tecnológicas tornou o quadro teórico da filosofia moderna metafísica ineficaz para legitimar a filosofia e a própria ciência. Tais transformações fizeram com 
que o saber científico e as instituições que dele dependem procurem novas formas de legitimação.

4 O pós-moderno, para Lyotard (2000), designa o estado da cultura após as transformações que afetaram as regras dos jogos da ciência, da literatura e das artes a partir do final do século XIX. Essas transformações são situadas em relação à crise dos metarrelatos de legitimação do saber científico e das instituições universitárias.

5 O processo de deslegitimação é decorrência da crise do saber científico, cujos sinais se multiplicam desde o final do século XIX. Esse processo não provém de uma proliferação fortuita das ciências, que seria ela mesma o efeito do progresso das técnicas de expansão do capitalismo. A deslegitimação procede da erosão interna do princípio de legitimação do saber seja ele fundamentado no dispositivo especulativo - formação do espírito absoluto - ou do dispositivo de emancipação - formação do sujeito livre, consciente e emancipado. No contexto pós-moderno, a ciência joga o seu próprio jogo. Ela não pode legitimar outros jogos de linguagem, mas antes de tudo, ela não pode mais legitimar a si mesma como supunha a especulação.

${ }^{6}$ A noção de jogos de linguagem é apresentada por Wittgenstein em sua obra Investigações Filosóficas (1994). Wittgenstein se depara com o aspecto pragmático presente no uso cotidiano que fazemos das expressões nas diferentes situações e contextos em que elas aparecem. Essa constatação conduz à formulação da noção de jogos de linguagem, que envolve não apenas expressões, mas também as atividades com as quais essas expressões estão interligadas. A noção de jogos de linguagem é explicitada por Wittgenstein como "o conjunto da linguagem e das atividades com as quais está interligada". Para Wittgenstein, os jogos de linguagem são múltiplos e variados; as únicas semelhanças que possuem são como que semelhanças de família. Entretanto, semelhança ou parentesco não significa identidade. A semelhança não envolve uma propriedade comum e invariável. Os jogos de linguagem estão aparentados uns com os outros de diversas e diferentes formas, e devido a esse parentesco que são denominados jogos de linguagem. Segundo Mauro Conde (2001), podemos dizer, com Wittgenstein, que não existe a linguagem, mas linguagens, isto é, diferentes usos das expressões linguísticas em diferentes jogos de linguagem. É com base nessa compreensão de jogos de linguagem que Lyotard procura analisar a crise dos metarrelatos legitimadores do saber científico e das instituições universitárias que deles dependem.

7 O conceito "Racionalidade Instrumental" foi utilizado nos trabalhos de M. Weber e dos frankfurtianos (especialmente M. Horkheimer) referindo-se ao processo de instrumentalização da razão assumido na ciência moderna. Um dos aspectos da racionalidade instrumental consiste em sustentar o monismo metodológico, como pressuposto, além de considerar que os conhecimentos a serem trabalhados nos cursos de formação devem ser imediatamente aplicados na prática dos professores. O conhecimento perde, com isso, seu valor de uso e assume o valor utilitário e funcional, passando a ser concebido como instrumento que deve possibilitar a construção de competências operacionais nos professores e a otimização de suas performances em sala de aula.

Artigo recebido em fevereiro 2013

Aprovado em março 2014. 